\title{
Trematode parasites of Mullet from Misurata, Libya
}

\author{
D.A.M.L. Al-Bassel ${ }^{1}$ and A.B. Ouhida ${ }^{2}$ \\ ${ }^{1}$ Higher Institute of Medical Technology, Misurata, Libya and ${ }^{2}$ Department of Zoology, Faculty of \\ Science, 7 October University, Misurata, Libya
}

\begin{abstract}
50 specimens of the Mullets Mugil cephalus were collected from the Libian coastal waters near Misurata city in Libya. 7 different species of trematodes isolated from the intestine of the mullets were briefly described. Haploporus benedenii, Haploporus lateralis, Lecithobotryes putrescens, Saccocoelium tensum, Saccocoelium gohari, Haplosplanchnus caudatus and Haplosplanchnus pachysomus. It is worthy to mention that, the present work is reported for the first time in Libya.
\end{abstract}

The mullets Mugil cephalus (Mugilidae) is considered a commercial marine fish in fish market.This species is omnivorous, feeds on plankton, thus it is more exposed to infection by trematodes than other marine fish, and is therefore selected for the present investigation. Libya was selected as the area since Mugil cephalus is a common species throughout most of the year. Although some information on the parasites of marine fishes from other areas is known, differences in the parasite fauna of a widely distributed species can be expected with different geographical locations (Manter, 1955). The objective of this investigation was to study the natural parasite fauna of the mullets from one region of its distribution and to extend our knowledge about the prevalence and distribution of trematode parasites in Mugil cephalus in the Mediterranean Sea in Libya. In Egypt, research has been done on mullets and its parasites (Al-Bassel, 1987, 1990).

\section{Materials and methods}

A total 50 fish belonging to Mugil cephalus were collected from the Libian coastal waters near Misurata city in Libya. Fish were brought fresh to the laboratory when they were antopised and examined for trematodes. Recovered trematodes was first relaxed, flattened then fixed in hot $70 \%$ alcohol. Parasites were examined then stained using aceto-alum carmine stain. Drawings were made to the scale using a camera Lucida. Measurements were in millimetres, unless otherwise stated. The identification of worms was performed according to (Yamaguti, 1971). The methods followed in collection, fixation, staining, clearing and mounting are described in Al-Bassel (1990).

\section{Results and Discussion}

All parasite species described below belonging to 2 families; Haploporidae and Haplosplanchnidae isolated from the intestine of the fish Mugil cephalus from the Mediterranean in Libya.These parasites include Haploporus benedenii (Stossich, 1887; Looss, 1902).

Haploporidae (Plate A Fig.1 and Plate C Fig. 1). Description was based on 3 specimens. The body is small in size and variable in shape, being egg-shaped $1.43 \times 0.45$. The length/width ratio is 2.53-2.70:1. The tegument is almost entirely beset with spines. The oral sucker is subterminal and fairly round in shape, it is frequently larger than the ventral sucker. The pharynx is oval in shape, muscular. The oesophagus is moderately long and leads into two intestinal caeca that may end at the middle of testis and measure 0.43 in length. The testis is round in shape, situated equatorially and measures 0.20 in diameter. Cirrus pouch is oval in shape, situated between pharynx and acetabulum, it measures $0.18 \times 0.17$. The ovary oval-shaped, it is smaller than the testis and measures 0.13 in diameter. Vitellaria in two compact spherical masses situated at the level of the two intestinal ends. Uterus lies at middle of the body. Egg measures $41 \times 24 \mu$. The excretory vesicle is succular and opened with terminal excretory pore. This species was originally described by Looss, 1902 from Mugil chelo from Triest and redescribed by Al-Bassel, 1990 from Lake Qarun in Egypt. The specimens were agreed fully with the major characters of the original description but the present report extends its geographic range to the Mediterranean in Libya. The present work represent a new host record.

Haploporus lateralis (Plate A Fig. 3 and Plate C Fig. 3). Description was based on 7 specimens. The body is oval or fusiform in shape and 
covered with minute spines, it measures $1.65 \times 0.54$. The length/ width ratio varies from $2.8-2.82: 1$. The oral sucker is fairly rounded, measuring 0.13 in diameter. The ventral sucker is almost round in shape, lies at the anterior half of the body and measures 0.17 in diameter. The pharynx is round in shape, leads to long oesophagus. The intestinal caeca are short and extending a short distance behind the acetabulum. Testis spherical in shape, it lies at the same level of ovary and measures 0.23 in diameter. Cirrus pouch is oval in shape, situated between pharynx and acetabulum, it measures $0.175 \times 0.17$. Ovary oval-shaped, it is smaller than the testis and measures 0.13 in diameter. Vitellaria in two compact spherical masses situated in front of the end of the intestinal caeca. Uterus lies at posterior half of the body. Egg measures $41 \times 24 \mu$. The excretory vesicle is succular and opened with terminal excretory pore. This species was redescribed by (Fares and Maillard, 1974) from Mugil capito from Frans. The present specimens are similar to Fares' $\mathrm{s}$ specimens in all characteristics except more details about geographic extention range to the Mediterranean in Libya. The present work represents new host record.

Lecithobotrys putrescens (Plate B Fig.5 and Plate D Fig. 5). Description was based on 5 specimens. The body is elongate, small in size and variable in shape, $1.78 \times 0.70$. The length/width ratio is $1.53-4.20: 1$. The tegument is almost entirely beset with spines. The oral sucker is larger than the ventral sucker, measuring $0.15 \times 0.18$.The prepharynx is long. The pharynx is small, being 0.11 in diameter. The oesophagus is moderately long and leads into two intestinal caeca; they may end at the middle of the body. The testis is round in shape, situated between the caeca and measures 0.190.29 in diameter. Cirrus pouch egg-shaped 0.19 $\times 0.15$. The ovary oval-shaped, it is smaller than the testis and measures 0.13 in diameter. Vitellaria are formed of 7 follicles on each side of the body. Uterus lies at middle of the body. Egg measures $40 \times 21 \mu$. The excretory vesicle is succular and opened with terminal excretory pore. This species was originally described by (Looss, 1902) from Mugil chelo from Triest and redescribed by Al-Bassel , 1987 from Liza ramada in lake Qarun in Egypt . The present work agreed fully with the major characters of the original description, but the present report extends its geographic range to the
Mediterranean in Libya. The present work represents new host record.

Saccocoelium tensum (Plate A Fig. 2 \& Plate C Fig. 2). Description was based on 23 specimens. The body is small elongate and rounded at both ends. It covered with minute spines, it measures $0.67 \times 0.24$. The length/ width ratio varies from 3.15-3.82:1. The oral sucker is subterminal and round, measuring 0.08 in diameter. The ventral sucker is almost round in shape, lies at the anterior half of the body and measures 0.09 in diameter. The pharynx is muscular and measures $0.06 \times 0.09$, leads to oesophagus 0.05 in length. The intestinal caeca are short and extending a short distance behind the acetabulum. Testis spherical in shape, it lies at the end of the body and measures 0.13 in diameter. Cirrus pouch is oval in shape, situated longitudinally between pharynx and acetabulum, it measures $0.15 \times 0.14$. Ovary oval-shaped, it is smaller than the testis and measures 0.085 in diameter. Vitellaria in two compact masses situated in front of the testis. Uterus lies at posterior half of the body. Egg measures $34 \times 17 \mu$. The excretory vesicle is tubular and opened with terminal excretory pore. This species was originally described by (Looss, 1902) from Mugil chelo from Triest. The present specimens are similar to the original description except the present work extends the range of distribution to the Mediterranean in Libya. The present work represents new host record.

Saccocoelium gohari (Plate B Fig. 4 and Plate D Fig. 4). Description was based on 6 specimens. The body is elongate and covered with minute spines, it measures $1.68 \times 0.30$. The length/ width ratio varies from 3.16-3.90:1. The oral sucker is round, measuring 0,175 in diameter. The ventral sucker smaller than the oral sucke and round in shape, lies at the anterior half of the body and measures 0.10 in diameter. The pharynx is muscular and spherical in shape, leads to long oesophagus. The intestinal caeca are short and extending a short distance behind the acetabulum. Testis elongate in shape, it lies in posterior half of the boy and measures 0.23 $\times 0.12$.Cirrus pouch is oval in shape, situated transversally between pharynx and acetabulum, it measures $0.18 \times 0.15$. Ovary smaller than the testis and measures 0.135 in diameter. Vitellaria in two compact masses situated at the end of the intestinl caeca. Uterus lies at posterior half of the body. Egg measures $39 \times 19 \mu$. The excretory vesicle is tubular and opened with terminal excretory pore. This species was originally 

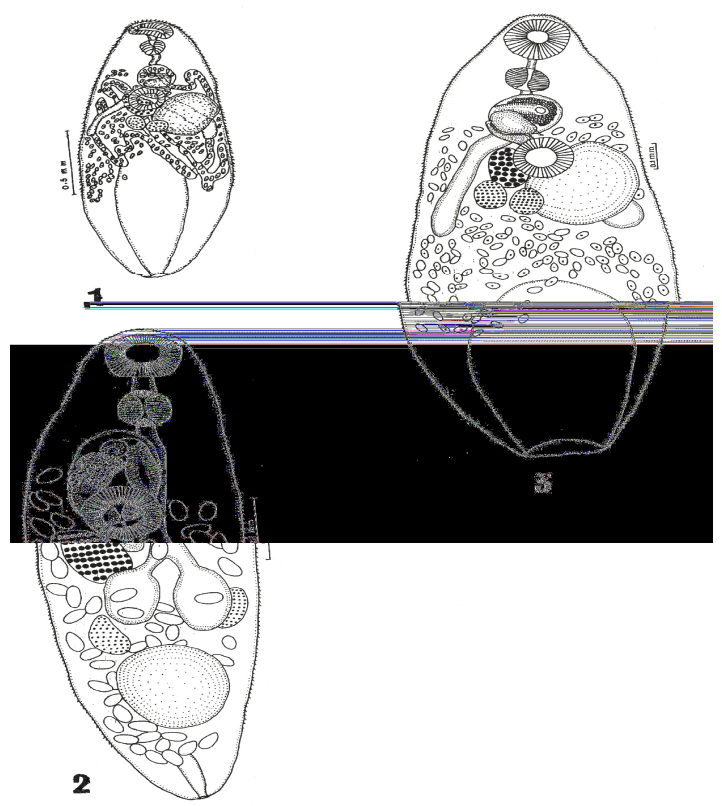

Plate (A)

1-Camera Lucida drawing of the ventral view of Haploporus benedenii (Scale par $0.5 \mathrm{~mm}$ )

2-Camera Lucida drawing of the ventral view of Saccocoelium tensum. (Scale par $0.1 \mathrm{~mm}$ )

3- Camera Lucida drawing of the ventral view of Haploporus lateralis. (Scale par $0.1 \mathrm{~mm}$ )
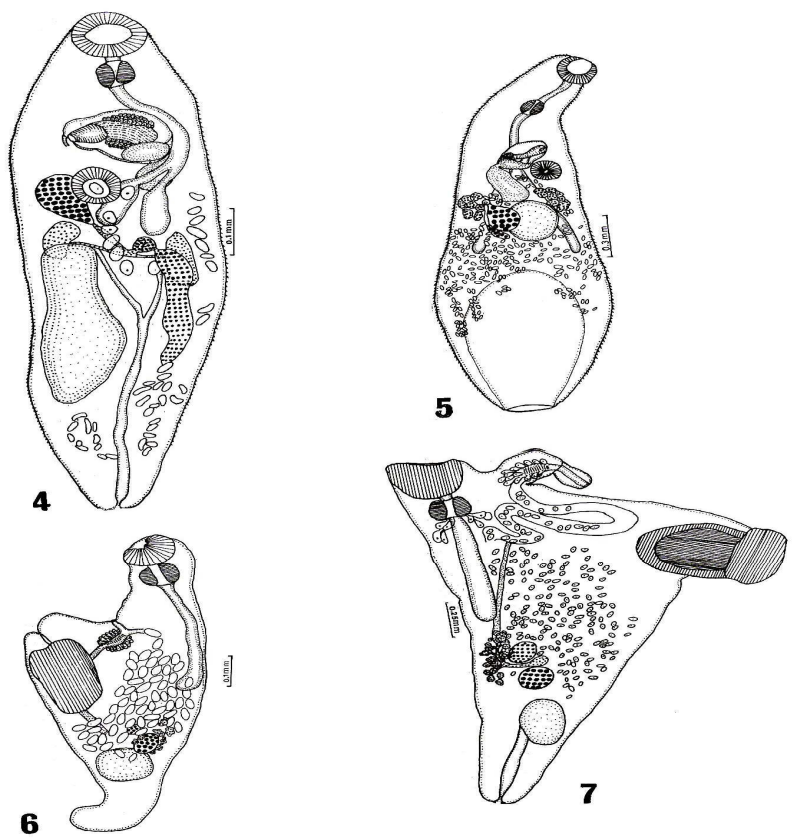

Plate (B)

4. Camera Lucida drawing of the ventral view of Saccocoelium gohari (Scale par $0.1 \mathrm{~mm}$ )

5. Camera Lucida drawing of the ventral view of Lecithobotrys putrescens (Scale par $0.3 \mathrm{~mm}$ )

6. Camera Lucida drawing of the ventrolateral view of Haplosplanchnus caudatus (Scale par $0.1 \mathrm{~mm}$ )

7. Camera Lucida drawing of the ventrolateral view of Haplosplanchnus pachysomus (Scale par $0.25 \mathrm{~mm}$ )

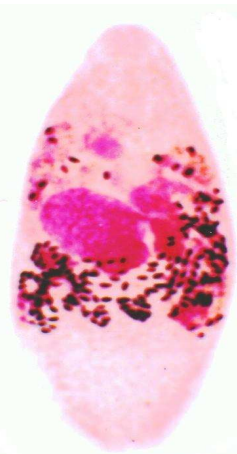

1

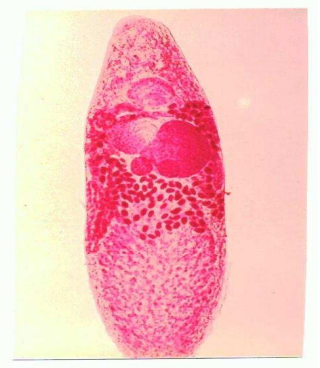

3

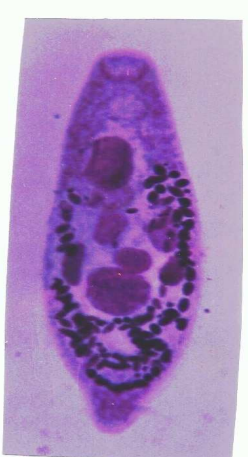

2

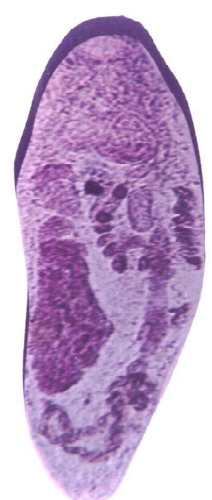

4

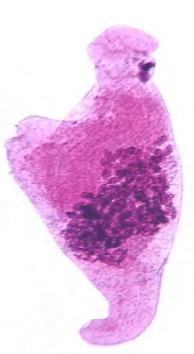

6

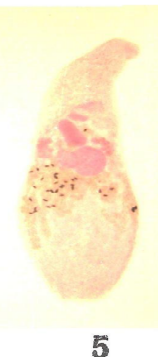

5

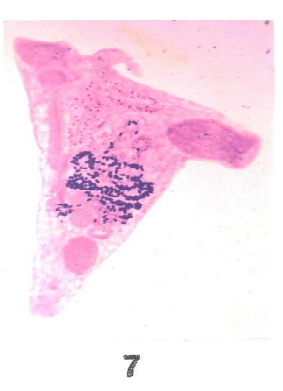

7
Plate (C).

1- Photomicrograph of the dorsal view of Haploporus benedenii. 2- Photomicrograph of. the ventral view of Saccocoelium tensum.
Plate (D)

4- Photomicrograph of the ventral view of Saccocoelium gohari. 5- Photomicrograph of the ventral view of Lecithobotrys putrescens.

6- Photomicrograph of. the ventrolateral view of Haplosplanchnus caudatus

7- Photomicrograph of the ventrolateral view of Haplosplanchnus pachysomus 
described by Al-Bassel, 1987 from Mugil capito from Lake Qarun in Egypt. The present description agreed fully with the original description, but the present report extends the range of distribution to the Mediterranean in Libya. The present work represents new host record.

Haplosplanchnus caudatus (Srivastava, 1939) Skrjabin and Guschanskaja, 1955, (Haplosplanchnidae) (Plate B Fig.6 and Plate D Fig. 6). Description was based on 7 specimens. The body is y-shaped with unequal arms and a curved tail-like structure at posterior extremity. It measures $2.05 \times 0.60$. The tegument has no spines. The length /width ratio is 1.20-7. 0:1. The oral sucker is subterminal and oval, measuring 0.24 in diameter. The ventral sucker is relatively long, club-shaped, may be retracted into body parenchyma. It lies on the right arm of the body and measures $0.60 \times 0.28$. The pharynx is muscular and spherical in shape, leads to long oesophagus. The intestinal caecum is simple straight tube and measures 0.60 long and ending at level with acetabulum. Testis spherical in shape, it lies at the posterior halh of the body and measures 0.32 in diameter. The vesicular seminalis is tubular in shape, it measures 1.15 in length. The genital pore lies in the angle included between the two arms. Ovary eggshaped, it is smaller than the testis and measures 0.15 in diameter.

Vitellaria are weakly developed, and situated beside the testis. Uterus restricted in small area in posterior half of the body. Egg large and measures $46 \times 23 \mu$. This species was originally described by Gupta and Ahmad, 1979 from Mugil chelo from india. The present specimens are similar to the original description except the present work are reported from new host and extend the range of distribution to the Mediterranean in Libya.

Haplosplanchnus pachysomus (Eysenhardt, 1829) Looss, 1902 (Haplosplanchnidae) (Plate B Fig.7 and Plate D Fig. 7). Description was based on 20 specimens. The entire worm is triangular in shape and measures $2.90 \times 0.85$. They are fairly large and fleshy parasites and in most of the fixed mature specimens both the ventral sucker and the genital papilla project prominently. The oral sucker is subterminal 0.21 $\times 0.33$. The ventral sucker is long and clubshaped, may be retracted into body parenchyma or projects prominently. It measures $0.35 \times 0.19$ and located in the left arm of the body. The pharynx is well developed. $0.18 \times 0.20$. The oesophagus cannot be distinguishelly from the intestinal cecum which is a simple straight structure extending up to the middle of the body, it measures 0.83 in length. The testis ovalshaped, lying near to the posterior extremity 0.35 $\times 0.22$. The genital atrium is tubular in shape. The ovary is pretesticular and spherical in shape, 0.15 in diameter. The vitelline follicles lie in one lateral field behind the end of caecum .The uterus extends up to ovarian complex. Eggs are elongate $41 \times 21 \mu$. Excretory vesicle $\mathrm{y}$-shaped with terminal excretory pore. H. pachysomus was described by Looss, 1902 from Mugil chelo in Triest. The present description is similar to the original description. The present work is reported for the first time in Libya, which represent a new host record.

\section{Reference}

Al-Bassel, D.A.M.L. (1987): A general survey on the helminth parasites of some fishes from Fayoum Governorate, Egypt. MSc. Thesis, Fac. Sci., Ain Shams Univ., Egypt.

Al-Bassel, D.A.M.L. (1990): Studies on the helminth parasites of some fishes from some inland water in Egypt. Ph.D. Thesis, Fac. Sci., Cairo Univ., Egypt.

Eysenhardt, H. W. (1829): Einiges uber eingeweide wumer Verh. Ges. Naturf. Fr.Berlin,1:144-152.

Fares , A. and Maillard, C. (1974): Research on some Haplopodidae (Trematoda) parasites of the mullet. Z. Parasitenk., 45:11-43.

Gupta ,V. and Ahmad ,T. (1979): Digenetic trematodes of marine fishes. On four new species of the genus Haplosplanchnus Looss, 1902 from marine fishes of Puri, Orissa. Helminthologia, 16:185-193.

Looss, A. (1902): Die Distomen unterfamilie der Haploporinae . Arch. Parasit., 6:129-143.

Manter, H.W. (1955): The zoogeography of trematodes of marine fishes. Exp. Parasitol., 4: 62-86.

Skrjabin K. I. and Guschanskaja (1955): Trematodes of Animal and Man. 10:579-616.

Srivastava, H. D. (1939): The morphology and systematic relationship of two new distomes of the family Haplosplanchnidae Poche,1925 from Indian marine fishes Ind. J. Vet. Sc. Anim. Husb., 9:67-71.

Stossich, M. (1887): Brani di elmintologia tergestina . Boll. Soc. Adriat. Sc. Nat. Trieste., 10:90-96.

Yamaguti S. (1971): Synopsis of Digenetic trematodes of Vertebrates. Tokyo, Keigaku Publ., 1074 pp.

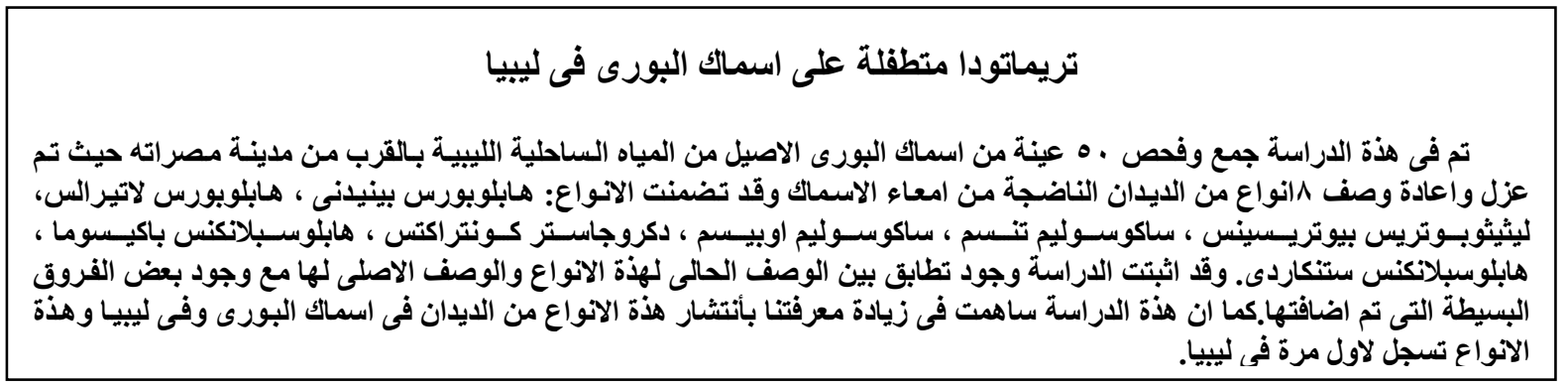


